\title{
Expensive or expansive? Learning the value of boundary crossing in design projects
}

\author{
Frederick M.C. van Amstel ${ }^{a}$, Vedran Zerjav ${ }^{a \neq}$, Timo Hartmann $^{a}$, Geert P.M.R. Dewulf ${ }^{a}$ and Mascha C. van der Voort ${ }^{b}$ \\ ${ }^{a}$ VISICO Center, Department of Construction Management \& Engineering and; ${ }^{b}$ Laboratory of Design, Production and Management, University \\ of Twente, P.O. Box 217, Enschede, The Netherlands
}

\begin{abstract}
Boundary crossing is a strategy as well as a tactic to bridge the gap between different activities in an organization. In design projects, boundary crossing is mainly associated with strategies such as multidisciplinary teams, integrated delivery methods and collaborative technologies. The value of these strategies in practice depends on the negotiation around the object of design, which is oriented to, on the one hand, exchange value, and, on the other hand, to use value. Learning the value of boundary crossing requires dealing with this specific contradiction at the boundaries of design projects. To let students learn the value of boundary crossing in this way, a board game that artificially introduces boundaries between players has been designed: The Expansive Hospital. This game was tested in a bachelor-level facility design course and the results suggest that knowing boundary-crossing strategies and having the necessary instruments alone do not necessarily lead to collaboration and sustainable expansion.
\end{abstract}

\section{ARTICLE HISTORY}

Received 4 September 2014

Accepted 5 November 2015

\section{KEYWORDS}

Design education; expansive learning; healthcare design; organizational boundaries; serious gaming

\section{Introduction}

Design projects are increasingly complex and fragmented. To cope with complexity, work is divided into separate activities, run by specialized professionals (Blau, 1984; Rau et al., 2012). These activities are connected by a common object of design (Engeström, 2006), which travels from one activity towards another in a production chain, supposedly increasing its value with each contribution. Since every activity aims for a return on its contribution, be that monetary or not, the object's value is split into two: the exchange value - for what can it be exchanged - and the use value - the practical usefulness (Engeström, 2000). In favour of exchange value, design activities eventually 'throw work over the boundary', disregarding use value and influencing the next activity to do the same. After going through a chain of activities that prioritize exchange value, the object might be completely devoid of use value - a commodity in the Marxist sense (Lefebvre, 1991; Engeström, 2000).

In project organization literature, boundaries are considered one of the main factors associated with the commodification of design objects, although not described in such Marxist terms. Boundaries are related to differences between organizational units and knowledge disciplines, which cause problems to communication, coordination and organizational cohesion (Carlile, 2004; Dossick and Neff, 2010; Neff et al., 2010; Pemsel and Widén, 2011). Project organization theories prescribe some strategies to deal with organizational boundaries: dissolve boundaries in temporary teams formed by representatives of different units and a neutral leader (Pahl et al., 1984, p. 139); skip boundaries by hiring a single organization to design and build the object (Cheng and Tsai, 2008); anticipate activities that happen later in the value chain by adopting an integrated project delivery method (Lahdenperä, 2012); or implement technology that makes boundaries visible and manageable in the object of design (Eastman et al., 2009; Singh et al., 2011).

These boundary-crossing strategies have proven difficult to apply in practice (Neff et al., 2010; Hartmann and Bresnen, 2011; Pemsel and Widén, 2011; Gottlieb and Haugbølle, 2013). The problems associated with boundaries cannot be solved in a simple way because they stem from an inherent feature of the division of labour: the contradiction between exchange value and use value (Lefebvre, 1991; Engeström, 2000). Even if organizational units and knowledge disciplines are strategically merged or homogenized, boundaries will still be active to justify the division of labour. Any homogenization

\footnotetext{
${ }^{\ddagger}$ Present address: Bartlett School of Construction and Project Management, University College London, 2nd floor, 1-19 Torrington Place, London WC1E 7HB, UK CONTACT Frederick M.C. van Amstel f.vanamstel@utwente.nl

(4) Supplemental data for this article can be accessed at http://www.dropbox.com/s/pa0cf4cdx141ck2/supplementary_game_walkthrough.mp4?dl=0.

(c) 2016 The Author(s). Published by Informa UK Limited, trading as Taylor \& Francis Group

This is an Open Access article distributed under the terms of the Creative Commons Attribution License (http://creativecommons.org/licenses/by/4.0/), which permits unrestricted use, distribution, and reproduction in any medium, provided the original work is properly cited.
} 
strategy will have to face the boundary-crossing tactics of difference preservation (Lefebvre, 1972), such as interfering with someone else's work, making undercover alliances and sabotage.

Boundary crossing, as a strategy or tactic, may cost more time and money than expected (Cicmil and Marshall, 2005); however, it may also expand the possibilities of generating unique value for the object of design (Miettinen and Paavola, 2014). Whether boundary crossing is expensive or expansive depends on the specific circumstance where it happens, or in other words, it is an emergent phenomenon (Akkerman and Bakker, 2011). Due to the limitation of predictive knowledge to learn about an emergent phenomenon, practitioners have to adopt a learn-by-doing approach to boundary crossing (Engeström et al., 1995).

If design practitioners learn the value of boundary crossing while crossing them, a difficult question is posed to design education: how can design students learn the value of boundary crossing if, for the most part of their study, they are working together under the same institution, the same discipline, playing almost the same role? The aim of this paper is, therefore, to advance further the understanding of boundary crossing in design projects and to explore how design students may learn boundary crossing from playing a game.

The game is called The Expansive Hospital in reference to the underlying theory: expansive learning (Engeström, 2015). This theory has been previously applied to study boundary crossing in many kinds of organizations, in particular, healthcare organizations (Kerosuo, 2004; Engeström, 2006; Engeström and Sannino, 2010). The Expansive Hospital artificially introduces boundaries among students and lets them experiment well-known boundary-crossing strategies and to develop their own boundary-crossing tactics. In spite of the name, if players do not cross boundaries or cross boundaries only to maximize exchange value, the hospital becomes expensive instead of expansive, leading to the hospital's bankruptcy and the consequent premature end of the game.

The game was brought to a bachelor-level facility design course to complement the assigned readings on boundary crossing. Playing the game followed the double stimulation method (Vygotsky, 1978; Engeström, 2011), which introduces an ambiguous situation among participants to observe emergent behaviour. This experimental method typically relies on small samples, diminished control and qualitative in-depth analysis. Our specific analysis is framed by the concept of boundaries developed by the expansive learning theory (Engeström, 2015) and the complementary concept of differences from the production of space theory (Lefebvre, 1972, 1991, 2014a, 2014b), both of Marxist origin. As a concept design game (Habraken and Gross, 1988), the purpose is to check the applicability of these concepts and, as a double stimulation experiment (Vygotsky, 1978; Engeström, 2011), the purpose is to validate the pedagogical approach of using games to learn boundary crossing.

The theories behind the game are firstly introduced, followed by the design process and the experimental method. The reports written by students who played the game are then used to reflect upon the value of boundary crossing in design projects as well as the possibilities of learning it by playing games.

\section{The emergence of boundaries between activities}

The expansive learning theory identifies boundaries in the connection between different activities (Engeström et al., 1995; Akkerman and Bakker, 2011). An activity is defined as a subject - individual or collective - transforming an object for a specific outcome, by means of instruments, rules and a division of labour (Engeström, 2015). Organizations are constituted of many activities connected by outcomes; what is produced by one activity becomes an element for another activity. For example, the outcome of design education activity may be among other things - students (subjects) capable of carrying on design activities in the industry.

Boundaries emerge amidst activities because the outcome is not used by the same activity, instead, by another activity. Each activity must generate an outcome, on the one hand, for exchange value - eventually measured in monetary terms - and, on the other hand, for use value - measured by the practical use of the outcome (Engeström, 2000). To generate unique outcomes and at the same time enable negotiation for profit, an activity must differentiate itself from the others, developing a different object, instrument, rule, community or division of labour. This process of differentiation has the side effect of creating boundaries among activities, perpetuating the contradiction.

To cope with the contradiction, the object of activity must be constantly reshaped according to the expected and the unexpected outcomes. In the face of an increasing demand and aiming for a larger profit, one activity might transform the object into a commodity that can be exchanged for almost anything at a low price, resulting in a high exchange value. The setback is that this object loses its unique qualities and usefulness, resulting in a lower use value. Any activity must negotiate the object value because, if it does not produce something unique, it may be taken over by another activity or delegated to automation (Kaptelinin and Uden, 2012) and, if it does not produce exchange value, it may not 
get the necessary resources, instruments or subjects from other activities.

The contradiction can be overcome, though, by a mutual effort from two or more activities to learn about each other and to prioritize use value. The object becomes coproduced and used by both activities, whose boundaries become a site for collaboration and co-creation of value (Ramirez, 1999; Vargo et al., 2008). The connection between activities expands from an exchanged outcome to a shared object (see Figure 1) (Engeström, 2001).

This expansion from exchanging outcomes to sharing objects is not permanent and does not eliminate boundaries or differences. Activities learn from their differences while working together, but such learning generates further differences that may hamper sharing. While some people might cross boundaries for the sake of learning, others might just want to interfere with a practice that is not beneficial for them. Boundary crossing, therefore, does not require or imply the consensus.

Eventually, specific instruments will be created to maintain the shared object despite the lack of consensus, the so-called 'boundary object' (Star, 2010). These terms - boundary object and shared object - are not to be confused here, since instruments can merely represent objects but not replace them (Hasu and Engeström, 2000). When the instrument of an activity is confused with the object of that activity, a significant reduction may be taking place: activity being reduced to a function of the instrument. This is often the case when a technology, a contract or an organizational chart imposes a different set of responsibilities, rules and division of labour to a chain of interconnected activities, in an attempt to strategically reshape boundaries. These instruments may become boundary objects but never shared objects that orient multiple activities; they are just a means for that orientation (see discussion in Akkerman and Bakker, 2011, p. 147).

The concept of boundary crossing (Suchman, 1994; Engeström et al., 1995) is related to the concept of
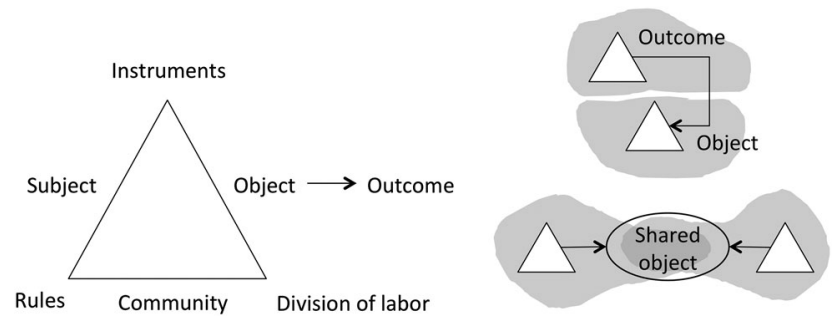

Figure 1 The activity system model (left), the outcome of one activity becoming the object of another (top right) and a shared object jointly produced by two different activities (bottom right, adapted from Engeström, 2001, p. 136). boundary spanning (Aldrich and Herker, 1977); however, there is a major distinction between them. Boundary crossing assumes that boundaries emerge through collective historical activity and cannot be shaped at will due to the materiality of contradictions, whereas boundary spanning assumes that boundaries are closure mechanisms that can indeed be managed by certain roles in an organization. The failure to acknowledge this distinction has spread confusion in boundary studies (Star, 2010; Akkerman and Bakker, 2011). Such confusion, we believe, stems from a knowledge gap between emergent and managed behaviour.

The production of space theory can fill this gap by linking boundaries to the process of activity differentiation. Boundaries are understood as the mark of an activity in space - disciplinary, organizational or physical space (Lefebvre, 1991, p. 191). Every time an activity is repeated, a difference arises, which can be of two kinds: induced and produced. Induced differences stay within the boundary (e.g. variation and improvement) and produced differences break through the boundary (e.g. antagonism and diversity). For instance, when activities are competing for exchange value, they induce differences that bring them small competitive advantages such as return-to-scale, while activities collaborating for use value produce differences that can complement each other - such as synergetic partnerships.

The theory also relates differences to strategies and tactics, which are coordination mechanisms among activities. Induced differences are coordinated by strategies, 'how groups tend to minimize the chances of maximal gain for their partners or adversaries - or conversely how they maximize their own minimal gain', whereas produced differences are coordinated by tactics that respond to adverse conditions with 'dissimulation, retreat, denial and misunderstanding' (Lefebvre, 1972, 2014b). These differences and coordination mechanisms appear simultaneously in opposition to each other, up to a point when there is an inversion: induced differences become produced and vice-versa. The turning point is when the tension generated by the contradiction between exchange value and use value is at the peak (Lefebvre, 1991, p. 372), which corresponds to the moment when boundaries become effective, that is, emerge.

An instrument that induces differences may not provoke boundary emergence at first; however, the induced differences may become produced if enough tension is raised. By default, produced differences deviate from induced ones, but they can also be forced back into the system. The transition from induced to produced entails the conflict for expanding differences whereas the transition from produced to induced entails the conflict for reducing them. 
The theory of expansive learning together with the production of space allows for grasping boundaries as an emergent phenomenon, fuelled by contradictions, shaped by differences and manifested as conflicts. This formulation can help to take a critical look at boundaries in design projects and to create an opportunity for expansive learning in design education.

\section{Dealing with boundaries in design projects}

There are many scholarly texts about boundary crossing in design projects (see Akkerman and Bakker, 2011 for a literature review on the topic). Some of these texts emphasize strategies to deal with boundaries - by inducing differences, while others emphasize tactics - by recognizing produced differences. Among the references mentioned in the introduction, we chose to discuss an engineering design textbook that focuses on boundarycrossing strategies (Pahl et al., 1984), and a case study on the design of a swimming pool that focuses on boundary-crossing tactics (Cicmil and Marshall, 2005). Both references include strategies and tactics, but they devote much more space to one or to the other.

The textbook's overarching strategy is a systematic approach for design: divide the object of design into independent tasks and subtasks; distribute them among specialized professionals; define interfaces for information transfer across the tasks and synthetize an overall solution. This approach allows for saving time with simultaneous or concurrent engineering of different parts of the system, but bears the risks of lack of information exchange and unsuitable solutions. To mitigate these risks, the textbook proposes organizing a temporary team freed of the current organizational boundaries and hierarchies, led by a project manager who oversees the big picture. 'Departmental boundaries are thereby transcended' (Pahl et al., 1984, p. 139).

Systematic approaches like this are the point of departure for the case study on the swimming pool. The project was organized in nested teams: the client team composed of client with architecture team - and the contractors' team - composed of many subcontractors. The architecture team was formed by the architect, the structural engineers and the building service engineers, all from different firms. The architect took the role of project manager and coordinated the different design activities. The two-stage procurement procedure anticipated the contractor's activity hoping to minimize the emergence of constructability too late in the process. Despite the strategy, 'the lack of trust and the persistence, of the old ways of doing things, attitudes and suspicions are perceived by the project participants to have caused tensions and problems' (Cicmil and Marshall, 2005).
The strategies did not prevent the project from running over schedule and added extra complexity for conflict management, which was dealt by improvised tactics. The study concludes that strategies are not enough to deal with boundary crossing in construction projects.

\section{The boundary-crossing challenge for design education}

Boundary crossing is a challenging topic for design education. Reading the literature mentioned above does not seem enough to learn boundary crossing since the associated conflicts needs to be experienced directly. In the expansive learning theory, this is expressed by the transition from object to instrument. When the text is the object of learning, students are evaluated by their capacity to reproduce the text - in an exam for instance (Engeström, 2015, p. 81). However, if students are stimulated to use texts as instruments for their learning activity, the object of learning becomes the same as in the work practice (Engeström, 2015, p. 99). The text is no longer used merely to achieve good grades, but to deal with a practical object, in the case of this challenge, crossing boundaries in a design project.

Design students typically learn how to organize projects through group assignments and design studios (Ward, 1990; Kuhn, 2001). When they are following the same course, chances are that they have similar backgrounds and interests. It is difficult to promote confrontation, especially when they can team up to divide the assignment into separate tasks and get a reasonable group grade out of it. Business simulations and concept design games have been tried in design education to provoke such a confrontation (Chanin and Shapiro, 1985; Habraken and Gross, 1988; Sacks et al., 2007; Bogers and Sproedt, 2012); however, they are typically based on abstract combinatory systems, with finite sets, which does not stimulate the creation of knowledge beyond the possible combinations, in other words, expansion (Hatchuel, 2001; Engeström, 2015). These games do not induce enough differences to make strong tensions and boundaries emerge between players; in fact, players more or less follow the same rules and display similar strategies.

Learning by doing in industry is difficult since complex design projects have too high stakes for students to directly partake. It is also difficult to cross boundaries between faculties to organize projects involving students from different design disciplines (Denton, 1997). The bottom line is that students rarely have the opportunity to experience boundary crossing directly.

Our response to this challenge is a board game designed to experience boundaries in a complex design project. The idea of creating a board game came after conducting three 
Table 1 Summary of boundary crossing strategies applied in healthcare construction projects and the requirements for the application of these strategies in the game

\begin{tabular}{|c|c|c|c|c|}
\hline $\begin{array}{l}\text { Boundary crossing } \\
\text { strategies }\end{array}$ & $\begin{array}{l}\text { Case } 1 \text { - Medical } \\
\text { imaging centre }\end{array}$ & Case 2 - Hospital lab & Case 3 - Elderly housing & $\begin{array}{l}\text { Requirements to implement the } \\
\text { strategy in the game }\end{array}$ \\
\hline $\begin{array}{l}\text { Temporary team (Pahl } \\
\text { et al., 1984) }\end{array}$ & $\begin{array}{l}\text { Building team with all } \\
\text { the construction } \\
\text { partners. }\end{array}$ & Concurrent engineering sessions. & $\begin{array}{l}\text { Building team with all the } \\
\text { construction partners. }\end{array}$ & $\begin{array}{l}\text { Players should be able to team up to } \\
\text { conduct a task together, but the team } \\
\text { formation shall not be fixed. }\end{array}$ \\
\hline $\begin{array}{l}\text { Overseeing leader (Pahl } \\
\text { et al., 1984) }\end{array}$ & Client. & Contractor. & Architect. & $\begin{array}{l}\text { There should be one role responsible } \\
\text { for giving directions and moderating } \\
\text { others. }\end{array}$ \\
\hline $\begin{array}{l}\text { Dividing tasks (Pahl et al., } \\
\text { 1984) }\end{array}$ & $\begin{array}{l}\text { A Gantt chart for every } \\
\text { partner. }\end{array}$ & A model for every partner. & Partners subcontracted. & $\begin{array}{l}\text { Player tasks should be clearly defined } \\
\text { in the construction contracts. }\end{array}$ \\
\hline $\begin{array}{l}\text { Collaborative } \\
\text { technologies, Building } \\
\text { Information Modelling } \\
\text { (Eastman et al., 2009) }\end{array}$ & $\begin{array}{l}\text { Online issue tracking } \\
\text { system and document } \\
\text { sharing (Project Place). }\end{array}$ & $\begin{array}{l}\text { Parametric modelling (Revit), } \\
\text { clash detection (Navisworks), } \\
\text { meetings with a big screen, and } \\
\text { file sharing (Docstream). }\end{array}$ & $\begin{array}{l}\text { Parametric modelling } \\
\text { (Revit), meetings with a big } \\
\text { screen, and file sharing } \\
\text { (Docstream). }\end{array}$ & $\begin{array}{l}\text { The hospital may be represented by } \\
\text { three dimensions blocks or by more } \\
\text { abstract representations such as } \\
\text { calculations and sketches. }\end{array}$ \\
\hline $\begin{array}{l}\text { Integrated delivery } \\
\text { (Lahdenperä, 2012) }\end{array}$ & Not adopted. & Not adopted. & Not adopted. & $\begin{array}{l}\text { There should be an integrated } \\
\text { contract to stimulate collaboration } \\
\text { among the construction team. }\end{array}$ \\
\hline
\end{tabular}

case studies in healthcare. The first case is a medical imaging centre with state-of-the-art diagnosing technique. The second case is a microbiology and pathology laboratory inside a medium-sized hospital. And the third is a combined housing and palliative care unit for the elderly. The main data set consists of partially transcribed semistructured or open interviews conducted with practitioners involved in the design process during the timeframe of investigation (2-3 months for each case). For the sake of space, a detailed account of these cases is not possible here; however, a summary of the boundary-crossing strategies found in these cases can be seen in Table 1, together with requirements to enable them in the game.

The board game was designed to communicate the findings of these case studies to a broader audience and to provide expansive learning opportunities for design students. The game is informed by case data, inspired by theory and developed according to the iterative design approach, which emphasizes playtesting prototypes to feel the gameplay and collect suggestions from players (Salen and Zimmerman, 2004, pp. 11-12).

Before the experiment with Bachelors students, the game was tested three times with Master's students and Ph.D. researchers. Every time it was tested, a map of issues was recorded in an Issue-Based Information System (Kunz and Rittel, 1970; Selvin et al., 2001) with the purpose of assisting reflection on what needs to be done next to improve the game. Adjustments followed. Iterating between designing and testing also contributed to sharpening the theory of boundaries based on activity differentiation, working similarly to pilot experiments and concept design games (Habraken and Gross, 1988).

\section{The Expansive Hospital Game}

The game plot is based on a hospital under constant expansion, in which all the profits are reinvested in real state. Each game session simulates a process that takes between 5 and 25 years of a typical hospital trajectory. Players design the hospital but also treat patients with the built facilities. Each patient successfully treated earns a point of credibility for the hospital. A hospital with no credibility points is closed and the game is over, whereas a hospital with 20 credibility points earns the excellence award and the winning condition is achieved. The game is also over when the hospital does not have money to pay the maintenance costs for the current facilities, a condition called bankruptcy in the game.

The rules are such that information will likely be lost during gameplay. The hospital is built with building blocks, each representing one facility type, with a pipework layer underneath. If players do not know what is already implemented, they cannot decide how to operate or what to build next. There is also a risk of clashing a gas pipe with an existing water pipe when adding extensions, allowing the contractor to charge an extra amount. Players receive squared 'database' sheets (see Figure 2) to keep track of information as they like, but that is not mandatory for playing and there is no instruction on how to fill them out. This is done to highlight the consequences of having or not having information readily available in negotiating with other players.

This is in a nutshell what players collaborate for. Conversely, there is a competitive side of the game. Each player choses one of six roles available, with mutually exclusive powers and a different way of earning money: the architect can design the building shape; the engineer can design the pipework; the builder can implement the designs; the hospital director can decide where to invest; the facility manager can maintain the facilities; and the nurse can admit and guide patients across the building. Players negotiate how to use their powers, charging the hospital heavily for their services, or harming others 


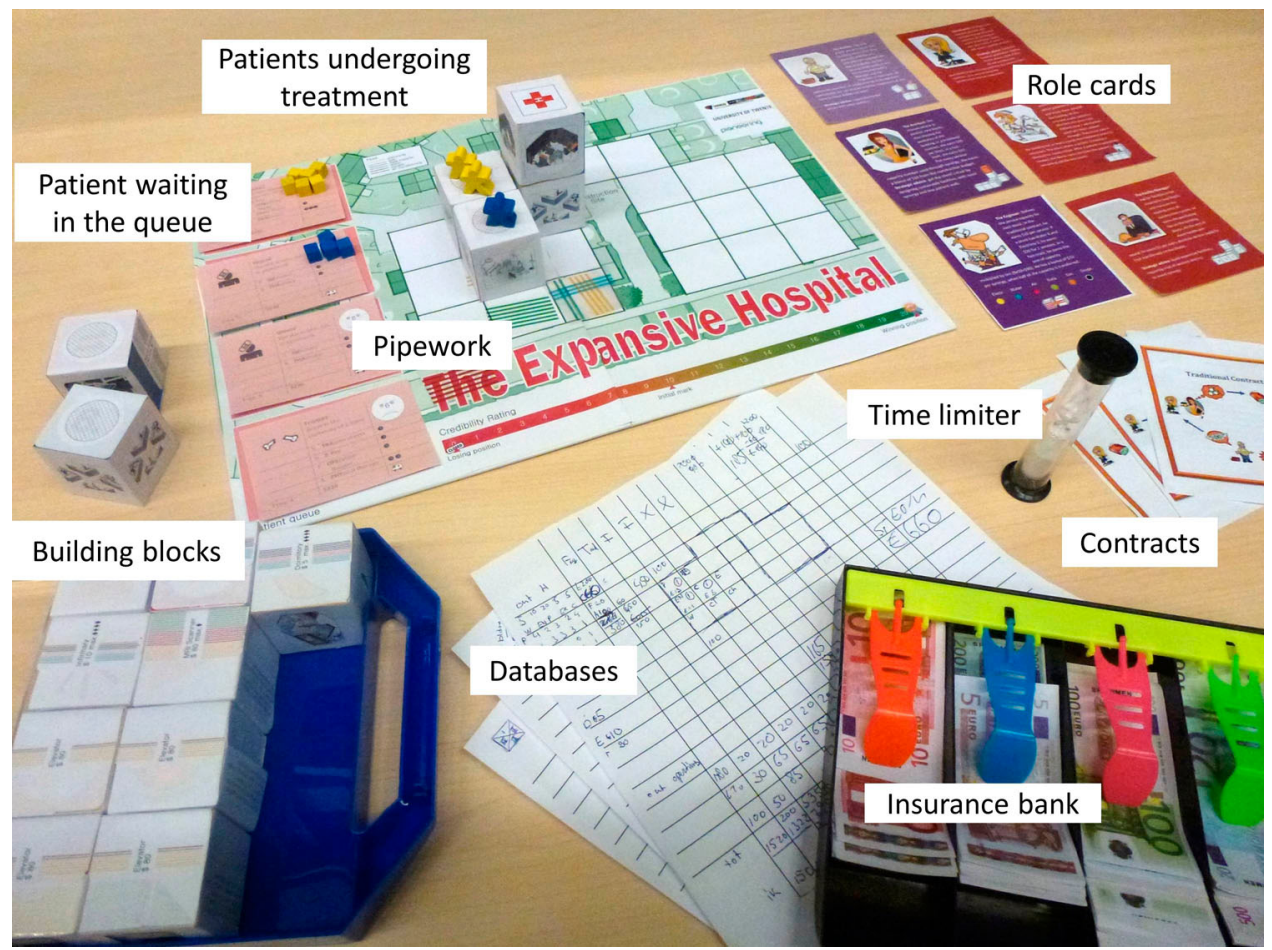

Figure 2 Components of The Expansive Hospital, a board game designed to learn boundary crossing.

players. If they play too competitively, the hospital quickly goes bankrupt; if they play too collaboratively, one of the players may have an advantage over the others.

The hospital is built in three dimensions with plastic blocks, which represent typical functions, for example, consulting room, operating theatre, trauma centre and so forth. These functions must be arranged according to their technical requirements - connection to water or heating pipes - and the needs of the patients waiting in the queue. Each block and each patient have different requirements according to function and illness, respectively. The treatment starts as soon as the hospital has the first function needed by the patient, then the rest must be built during the treatment. The hospital earns a fee once the treatment is completed.

The money flows from the insurance company to the hospital account and then to player accounts. The architect, contractor and engineer earn money in the construction round, while the hospital director, facility manager and nurse earn their fees in the healthcare round. The hospital design is supposed to be developed and implemented during the construction round by the construction players; however, the healthcare players may discuss and influence the design in both rounds. Each player has his own turn to make decisions within the round, but since the decisions are immediately visible, they are often questioned and renegotiated.

Due to this game flow, a player's decisions depend very much on other players, but the dependences are not symmetrical. Each player plays a different game mechanics (Table 2), but they all affect each other in unpredictable ways due to the large number of possible choices for each player. The unpredictability allows each player to have a negotiation margin: players are expected to be too busy with their own mechanics to

Table 2 Game mechanics identified by boardgamegeexk.com that applies to players in the Expansive Hospital game; each player plays a different game mechanics

\begin{tabular}{|c|c|c|c|}
\hline Role & $\begin{array}{c}\text { Game mechanics } \\
\text { (boardgamegeek.com) }\end{array}$ & Application in The Expansive Hospital & $\begin{array}{l}\text { Board game consulted and/or played as } \\
\text { a reference }\end{array}$ \\
\hline Nurse & Worker placement & Moving patient meeples ${ }^{\mathrm{a}}$ & The Pillars of the Earth (2006) \\
\hline $\begin{array}{l}\text { Facility } \\
\text { manager }\end{array}$ & Secret unit deployment & $\begin{array}{l}\text { Knowing the pipework but hiding it from the others to build } \\
\text { more than necessary }\end{array}$ & $\begin{array}{l}\text { Cleopatra and the Society of Architects } \\
\text { (2006) }\end{array}$ \\
\hline Director & Commodity speculation & Investing in facilities and patients that look more profitable & 1830: Railways \& Robber Barons (1986) \\
\hline Architect & Pattern building & Designing a building that looks good in his opinion & Ugg-Tect (2009) \\
\hline Engineer & Tile placement, pattern building & Resolving the puzzle of pipework tiles & Tsuru (2004) \\
\hline Contractor & Auction/bidding & Bidding for a construction contract & Master Builder (2008) \\
\hline
\end{tabular}


understand what is going on with other players. The complexity of game mechanics makes this game very open-ended and prone to unexpected behaviours (see supplemental video content presenting the game mechanics).

Differences are induced between players in the hopes that they will experience boundaries while playing. If player roles are considered self-standing activity systems (see Figure 1), the differences induced are within their object, their instrument, their rules, their community and their division of labour (see Table A1 in the appendix). These activity systems, however, are not historically constituted and cannot stand as such; the activity system model is meant to understand change from one structure to another in an existing activity and not to impose an empty structure to an activity (Engeström, 2015). Play is indeed an activity, but an activity that enacts another activity through imagination (Vygotsky, 1967). The contradictions inherent to the activity being enacted also manifest in play, though in less tension (Engeström, 2015, p. 106). We believe that if enough tension is raised by play activity, players may fully embody their roles and produce their own differences, characterizing the formation of their own activities. In contrast, if little tension is raised, players will just follow the rules and invest no further motives in their objects. This is, nevertheless, expected at the beginning of the game, when players are still trying to understand the game rules. If they do not manage to go beyond following the rules and embody their roles, no boundaries will be played at all.

The game stimulates players to produce their own differences via the contradiction between exchange value and use value. If rules are followed mechanistically, the hospital goes quickly bankrupt since player's' outcomes are measured by money and not by usefulness - exchange value, not use value. The usefulness of a player's outcome can only be realized by relating it to the emergent qualities of the hospital: (a) capacity to adapt to fluctuations in patient queue; (b) reasonable maintenance costs; (c) cooperative crew. Use value becomes clearer through emergent collaboration, whereas exchange value becomes clearer through emergent competition. In other words, players must collaborate for use value while competing for exchange value. Easy compromises are not possible once boundaries are under effect. The game suggests strategies to cross boundaries (Table 2), but the tactics are not given.

The main strategy at the disposal of the hospital director - the overseeing leader - is to change the contract with construction players every round. There are three types of contracts derived from the Dutch regulations (Bruggeman et al., 2010): the traditional contract when the architect helps defining a design and a budget before asking the contractor's opinion; the fast-track contract - when the contractor is responsible for everything, including paying the architect and engineer according to standardized fees; and the integrated contract - when the director defines a fixed budget for the construction players whose income can be freely negotiated. These contracts can be used to moderate players, for example, by changing from fast-track to traditional if the contractor is overcharging. However, the moderation can always be countered. In the same example, the contractor may refuse to bid for a traditional contract, halting all the construction work in the game.

To summarize, the game is a caricature of a hospital project and also an open system for the emergence of ambiguity, uncertainty and overwhelming complexity that are so typical of project-based organizations (Cicmil and Marshall, 2005; Chinowsky, 2011; Askland et al., 2013).

\section{Experimental method}

The Expansive Hospital was introduced in a facility design course from a Civil Engineering Bachelors programme to let students learn boundary crossing beyond what texts say about it. The course consists of an engineering design introduction based on the textbook by Pahl et al. (1984), alternating between lectures and hands-on sessions for group assignments. The first lectures introduce the difficulty of representing knowledge in design instruments such as Building Information Modelling (BIM) (Eastman et al., 2009) and the importance of maintaining a reflective practice (Schön, 1983). After these lectures, the board game was introduced in a hands-on session with the goal of letting students directly face the issues discussed by literature. Before the session, students were individually required to write a report about the study of the swimming pool project (Cicmil and Marshall, 2005). The assignment asked: 'Is it possible to reduce the risks of concurrent design activities, by using a two-stage tender process or other collaborative design methods?' After playing the game, they were also requested to write another report reflecting on the gaming experience, this time in a group.

Students organized themselves in groups of six, making in total seven groups simultaneously playing the game. The game was introduced without explanations; game mechanics had to be picked up from the rulebook or by asking questions to the teachers at the class. ${ }^{1}$ It took an average of one hour to understand all the rules and to achieve a smooth game flow; two hours was the total duration of the session. The learning reports were collected, coded and analysed according to the activity system 
model (Figure 1), looking for evidence of produced differences (Lefebvre, 1972, 1991) within the enacted activities. The produced differences are used as a measure for the emergence of boundaries among players and also of expansive learning, which here means learning beyond the text. For the sake of space, only two groups are discussed in this study: the group who performed the best and the group who performed the worst according to the game's quantitative outcomes.

The experiment with students has two aims: to sharpen the boundary-related concepts that inspired the game creation and to test the pedagogical approach of learning boundary crossing by playing a game. The method is a combination of concept design game and double stimulation. 'Concept design games are research tools intended to help us better understand designing. They do this by opening to scrutiny the concepts we use as designers, as well as the structures of the complex artifacts we manipulate' (Habraken and Gross, 1988 , p. 152). And double stimulation is a psychological method to study learning, taking the process more into account than its outcome (Vygotsky, 1978; Engeström, 2011). The first stimulus is a contradictory situation and the second stimulus is an ambiguous instrument that may be used to overcome contradictions. The experiment looks at how subjects make the second external stimulus their own internal stimulus, that is, how they resolve the ambiguity and give a certain meaning to the instrument. The instrument helps to objectify meaning making, what helps not only the experimenter but also the learner.

In the experiment presented here, the interdependence between players is considered to be the situation where the contradiction between exchange value and use value manifests and the database sheet is the purposefully introduced ambiguous instrument. Other game components as well as anything participants bring to the experiment - e.g. a notebook or an electronic calculator - may also be appropriated as a second stimulus. Since the second stimulus is considered to be the underpinning for learning (Vygotsky, 1978), it is expected that it is mentioned in the learning reports delivered by students. A good deal of interpretation based on the aforementioned theories is employed to identify this stimulus among the many others reported.

The task of writing the report can also be considered a contradictory situation in itself, since no clear explanation about what to learn from the game was provided. The instruction given was to relate the learning experience to the texts previously assigned for reading (Schön, 1983; Pahl et al., 1984; Cicmil and Marshall, 2005; Eastman et al., 2009), which can also be considered an ambiguous tool given for the task of writing the learning report. The double stimulation method was in fact a pedagogical premise of the whole course programme, which aimed to take into account and support individual and group development. In the present study, the learning reports written before and after the session are compared to find evidence of this development.

\section{Experiment results and analysis}

Student reports mention many attempts to influence other players decision's to come along and exchange information, to use common visualizations, to help with a task outside of own expertise and to co-create solutions, actions typically associated with boundary crossing (as described by Akkerman and Bakker, 2011). Despite trying similar strategies and playing the same game, the performances of these two groups were completely different: group A managed to build a working hospital and group B was bankrupt before treating any patient. The sum of earnings in group A was almost five times larger than group B, meaning that its hospital financial capital increased way beyond the initial 2000 (Table 3). The analysis of the reports that follows tries to explain these results through the theory of boundary emergence from activity differentiation.

\section{Shared objects in group A}

Group A used the databases as instruments for storage and design. The hospital director made an income statement; the facility manager represented the position of the blocks already built; the engineer made one sketch and the nurse had a sophisticated care plan including the facilities needed for the current admitted patients and the number of satisfaction points expected to be spent (Figure 3). The nurse was the only one who used the

Table 3 Accumulated earnings for each player role, in game's money

\begin{tabular}{llr}
\hline Gr. & \multicolumn{1}{c}{ Player role } & Accumulated earning \\
\hline A & Nurse & 2400 \\
& Facility manager & 3400 \\
& Director & 2225 \\
& Architect & 350 \\
& Engineer & 1320 \\
& Contractor & 210 \\
& Total paid by the hospital & $\mathbf{9 9 0 5}$ \\
& Nurse & 0 \\
B & Facility manager & 430 \\
& Director & 80 \\
& Architect & 470 \\
& Engineer & 680 \\
& Contractor & 200 \\
& Total paid by the hospital & $\mathbf{1 8 6 0}$ \\
\hline
\end{tabular}

Notes: In group $B$, the nurse did not earn anything because no patient was treated. Group A manages to treat many patients within the same amount of playing time ( 2 hours). 

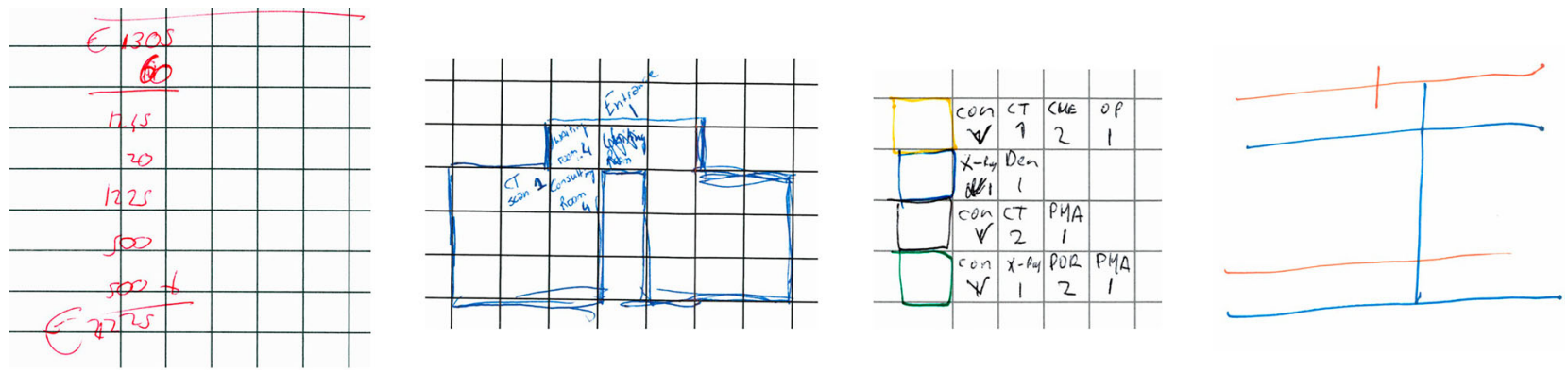

Figure 3 Players from group A used their 'databases' to represent their own object: (a) the hospital director created a financial spread sheet, (b) the facility manager created a facility map with the number of pipes per room, (c) the nurse created a care plan per patient, represented as a coloured row, and the engineer freely sketched the pipework with different colours. The architect and the contractor did not use their own databases.

database to represent future situations instead of just taking notes of what was already built, what could be considered an expansive use of BIM (Hannele et al., 2012; Miettinen and Paavola, 2014).

The nurse had a holistic view on patients, considering not just the queue, but also patients inside the hospital and future patients who did not even show up in the queue. His object was shared with the facility manager and the hospital director, who worked together to maximize patient admission and discharge. Oriented to this object, the healthcare team gradually developed a vision of a profitable hospital guided by the rules of operation efficiency. They convinced the construction team to charge less and less for their work, up to the point that they discovered a weakness in the game's rule: the integrated contract allowed conducting inspections for free, meaning that the contractor could simply lift a block to see the hidden pipework. That is not a beneficial action for the contractor, but he did not manage to convince the other players to do otherwise.

The result is that the contractor was the last in the group, but the group managed to collect much more money overall. The construction team did not hamper the game in order to avoid the loss of exchange value. They were so involved with the challenge of designing integrated facilities that they did not mind losing the game at the individual level. The differences produced by players in group A (Table A2 in the appendix) suggest the existence of two shared objects that reinforce each other: the patients generate profits for the hospital, and those profits are reinvested in the design of integrated facilities, with the aim of treating even more patients (Figure 4).

\section{Exchanged outcomes in group B}

The healthcare team from group B did not have a shared object. Players acted in an individualistic basis, with not much regard for the teams they belonged to. The following excerpt from the learning report summarizes the situation:

According to the rules of the game there should be two teams; the construction team and the healthcare team. There was no consultation between the players on the

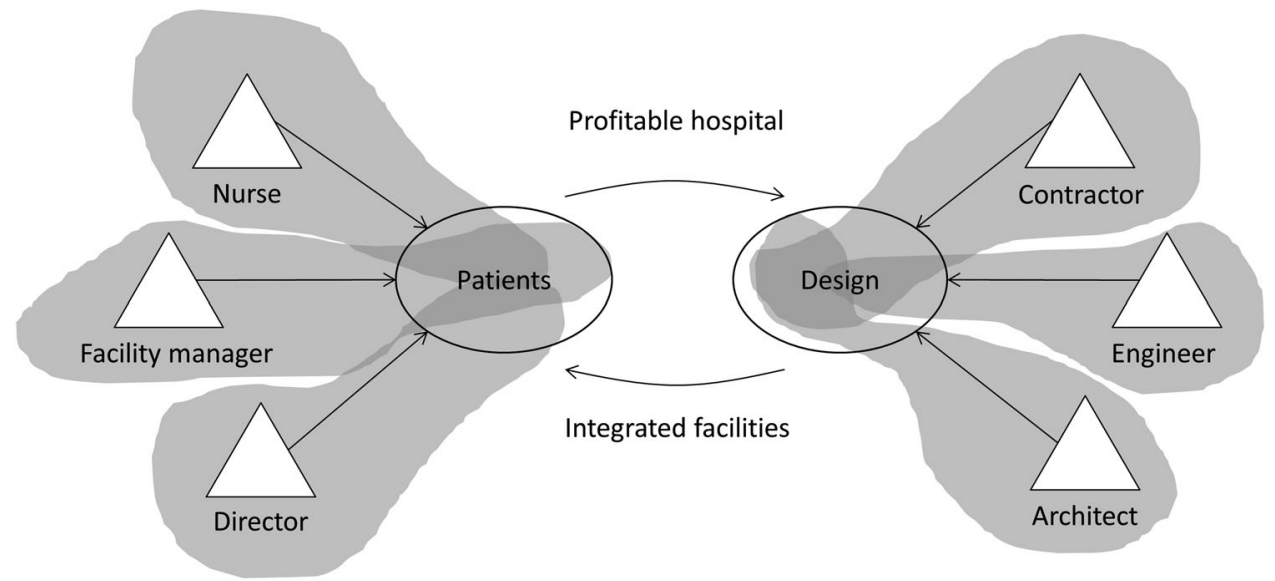

Figure 4 Interconnected activity systems in group A: the healthcare team collaborates for patients while the construction team collaborates for design. The exchanges between these objects reinforce each other. 
healthcare team, which resulted in building unnecessary facilities, and going over budget. In the construction team there was a bit of collaboration, mostly to figure out the best way to maximize their income and bring the hospital further in debt. This resulted in the hospital going bankrupt in three rounds and the construction team having their pockets filled with cash. It was clear that no one had a long-term vision and was only in it to win personally, instead of reaching the team goal. (Group B, excerpt from learning report after playing the game)

Players from group B followed strictly the rules, but spent an insurmountable amount of time in negotiating outcomes, mainly to protect individual interests. After giving up negotiating, a player would throw his work to the next player just to keep the game going on, but the quality of that work was already compromised. The collaboration among the architect, engineer and contractor can be considered a shared object, yet one that produces a completely useless building due to its extreme tendency towards exchange value (Figure 5). This object fails to feed the nurse with more patients and the game was over after three rounds due to the lack of money to build new blocks and to maintain the current ones. The activities organized themselves as a chain, connected mostly by the mandatories demands and supplies prescribed by the rules. Since using the database sheet was not mandatory, none of the players did it. It is possible

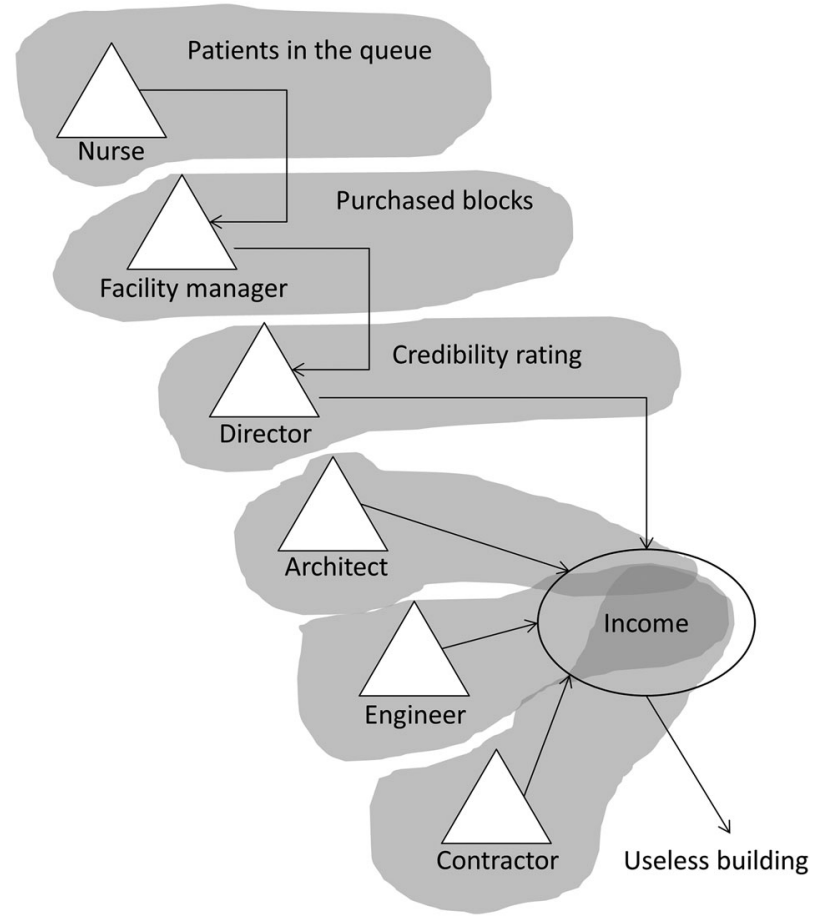

Figure $\mathbf{5}$ Interconnected activity systems in group B: healthcare players throw their outcomes over the boundary until the object is emptied of use value by the construction players. The value chain ends up in a useless building that cannot serve as an object to generate patient income. to conclude from this analysis that group B produced fewer differences than group A (see also the appendix).

\section{Groups compared}

The emergent boundaries in group B form the pattern of a value chain: one activity delivering work to another activity, each adding value to a common object of production. The value of this object, however, was increased in terms of exchange, but not in terms of use, resulting in a very expensive and useless building. The emergent boundaries in group A do not form the pattern of a value chain; instead, it resembles the description of a value constellation, characterized by the co-creation of (use) value (Ramirez, 1999; Vargo et al., 2008).

The varied organization morphology within these two groups highlights the importance of not taking boundaries, boundary crossing, shared objects or instruments for granted. The game introduced the same conditions for all the groups, but each group created its own boundaries based on the interpretation of the rules, social relationships within the group, personal experiences and other elements. Some groups used the building blocks, some used the information database and some used concepts such as 'the need to collaborate' as instruments to cross the boundaries.

The players enacted six different activities in both groups, corresponding to player roles as designed. None of the players enacted two or more activities, yet this was observed in a previous testing session, when an architect took over the work of an engineer who was not able to understand his role and negotiate a position. In this specific session, the boundary between the architect and engineer could be considered reduced or even dissolved. Nevertheless, in the present experiment, all players' activities deviated from the differences induced by the game rules and, therefore, had their own boundaries (see Table A2 in the appendix for a full account).

\section{Learning as reported by students}

The comparison between the learning reports before and after playing the game suggests that students underwent a reality check on boundary-crossing strategies such as two-stage tendering, collaborative technologies and integrated delivery. Despite reading about the strategies from Pahl et al. (1984) and knowing their pitfalls from Cicmil \& Marshall (Cicmil and Marshall, 2005), students could not simply apply the strategies and avoid the pitfalls. Once embodied in their game roles, they realized that it was difficult to give up personal gains in favour of group gains, no matter how rational the argument was. Group B blamed the lack of a common goal among the 
players for the early bankruptcy. Conversely, group A affirmed having a common goal but also individual goals, which became difficult to distinguish due to the ambiguity of players' action and talk. Sometimes players would act for the group benefit, sometimes for their own personal benefit and sometimes for both.

Despite not using the database sheets, group B reports to have experienced some principles behind BIM (Eastman et al., 2009), a collaborative technology strategy for boundary crossing:

While playing this game we noticed that the visualization of the hospital was very helpful. Not only for the communication in the teams but also for the overall game play. While the health care team or the construction team was arguing, the visualization was helpful in order to choose which decisions would be right to make. [ ... ] The visualization of the hospital, the result of working on a BIM (Building Information Modelling) principle, contributed to the learning process of the game. [...] A BIM tool is useful to implement much information within one model. (Group B, excerpt from learning report after playing the game)

Group B used the building blocks as a single model (a boundary object) to plan and design, whereas group A used multiple database sheets to do so. The database sheets allowed group A to look beyond the task at hand, in particular through the database made by the nurse (see Figure 3). Instead of confirming the advantages proclaimed by the text read for a previous lecture (Eastman et al., 2009), group A developed a critical view towards BIM:

A very important feature of BIM is that information of various disciplines is shared. This provides insight in the other areas of the facility. This can be used to adapt to each other, but during the game this insight created a problem. The problem was that every player from the various disciplines wanted to get involved with the other disciplines to increase their own gain. The players became selfish. (Group A, learning report after playing the game)

This critical view represents a considerable expansion from what students knew before playing the game from reading Pahl et al. (1984) and Cicmil and Marshall (2005), as can be seen from these excerpts from the individual reports before playing the game:

In bigger designing projects, which require multiple design teams, there is a need for a clear structure in the designing process (Pahl and Beitz, 2007, p. 138). Also process steps have to be independent, (Pahl and Beitz, 2007). The result is that design teams can carry out their process without interfering with each other. (Student R.H, group A, excerpt from learning report before playing the game)

[BIM] gives a digital representation of the physical and functional characteristics of the project. [...] So that people from the management side and the construction and design side do not only see the processes from their own point of view. BIM gives them more insight, which leads to more understanding of each other. (Student J.R, group A, excerpt from learning report before playing the game)

Group B did not manifest any critical stance towards the literature provided in the course; however, the reflection about the failed experience of building a working hospital reveals a deeper understanding of the underlying contradiction:

When one person decides to only go for his own goal and personal gain this can quickly affect the entire group. The consequence of this is that this person gains a short-term advantage at the cost of everyone's long term. This stems from the fact that this one person can tax the entire system in such a way that the other roles in the project do not have enough leeway to fulfil their own personal goals. When every person keeps the different goals of the different person in mind they can take this in to account when taking their own decisions and everyone can work together working on solution which brings good long term advantages. (Group B, excerpt from learning report after playing the game)

The comparative analysis suggests that both groups have expanded their understanding of boundary crossing beyond the explanations and prescriptions provided by the selected literature. Expansive learning was not caused by the game, but by the joint effort of students trying to cross boundaries and later reflecting about it in the report. In the learning process, the game can be credited for offering a certain resistance to the application of strategies prescribed by the literature.

The experiment results suggest that avoiding boundary crossing by defining clear boundaries, instruments and deliverables does not seem to be enough to salvage use value. The game setup had all of these conditions, but the players eventually transformed them into opportunities to increase exchange value. Dealing with the contradiction depended more on the motivation behind players' activities than on the ambiguous instrument provided by the game setup. Hence, the investment of motives into shared objects can be considered the meaning of the second stimulus achieved by players when dealing with the contradiction between exchange value and use value.

\section{Discussion}

This study suggests that knowing boundary-crossing strategies and having the necessary instruments do not necessarily lead to collaboration in design projects. If it is possible to extend the analogy between project-based organizations and games to the present study, boundary crossing requires more than to understand the spoken 
and unspoken 'rules of the game' (Askland et al., 2013, p. 120; Räisänen and Löwstedt, 2014, p. 4). In fact, boundaries are liminal spaces where the institutionalized rules of each activity are suspended and new rules can be created (Räisänen and Löwstedt, 2014). This can be exemplified by the negotiated free of charge inspection in group $\mathrm{A}$, which worked against the contractor's interest. The rules were not the only differences produced, though; they have been observed in instruments, objects, outcomes and the division of labour (the appendix). The production of differences in players' activities provides 'insight into how agents - individuals or organizations - attain the 'feel of the game' which is required in order to be a practitioner within the project organizational field or a project organization field' (Askland et al., 2013, p. 125).

A major limitation of this study is that the learning reports do not track the development of the second stimulus in sufficient level of detail. In studies of expansive learning, data collection typically relies on direct observation and/or video recording (Engeström, 2011). We have chosen not to record the session due to the possibility of students feeling uneasy and exposed during the execution of a graded assignment. In future works, we expect to experiment on the game with students from different backgrounds and with experienced practitioners, as part of a long-term intervention in an existing design project organization. In such a context, video recording might seem more appropriate, thus enabling a fine-grained analysis of the second stimulus.

In this experiment, we have observed that even when there is little shared space between production and consumption - in the game's term the construction and the operation round, consumption make its way through design by own effort. In other words, there is also production in consumption, which is in fact the production of use value (Lefebvre, 1991, 2014a). The game could have been designed to take only the boundaries in production into account, with greater detail on the division of labour and the design instruments, making a much more realistic image of what BIM can be. However, we preferred to emphasize the interplay between the use value generated mainly at consumption and the exchange value generated mainly during production, which is actually the main source of conflict in the game. Humour, as implied by the caricature depicted by the game, enabled the emergence of a counter-discourse (Gonzatto et al., 2010) in group $\mathrm{A}$ : the criticism on BIM, which can also be found in some other texts in the literature (Holzer, 2007; Dossick and Neff, 2010; Miettinen and Paavola, 2014).

Boundaries have been presented here as the contour of fluid organizations, a marginal effect of the production of space among activities. This perspective is relatively new, since most investigation on boundaries often falls to a determinism of knowledge specialization, resulting in compartmentalization or silos in organizations (Carlile, 2004; Dossick and Neff, 2010). They justify the need for instruments (Carlile, 2002; Forgues et al., 2009) or professionals (Kelley and Van Patter, 2005; Brown, 2008) that are capable of integrating knowledge at the boundary in a neutral or holistic way, ultimately reducing the differences among the activities. The political difficulty of keeping boundary work neutral or even the fallacy of such discourse pushes to think beyond knowledge consolidation as a strategy to manage work fragmentation. While some researchers think about reducing differences and reassembling totalities, practitioners are already tying the knots, crossing boundaries on a daily basis to get work done (Engeström, 2008). Apparently, they do not seek to integrate knowledge, but to create new knowledge that can fill in the gaps and expand the practice, one difference at a time (Engeström et al., 1995).

\section{Conclusions}

This study contributes to the expansion of project-based organization research towards social, cultural and managerial boundaries (Chinowsky, 2011; Pemsel and Widén, 2011; Askland et al., 2013; Räisänen and Löwstedt, 2014), in particular, with a theory of boundaries based on activity differentiation. According to this theory, boundaries emerge between activities when the differences in their structure (subject, object, instrument, rules, community and division of labour) activate the contradiction between exchange value and use value. These differences can turn into competitive advantages or collaborative partnerships, depending on how the contradiction is resolved.

To test this theory and to provide a learning opportunity for design students, a board game has been designed and tested in a facility design course. The findings of this experiment are consistent with another study on construction projects which found that organizational boundaries cannot be completely eliminated by integrative strategies (Baiden et al., 2006). In fact, the group of students who blindly applied integrative strategies failed to produce a design object with use value. In contrast, the group that developed provisional tactics to deal with boundaries produced differences that enriched both the use value and the exchange value of the design object. The production of these complementary differences can be attributed to the emergence of the second stimulus - the motivation towards shared objects. That stimulus was an internal, not external factor; an act of volition to overcome the contradiction between exchange value and use value. 
The recommendation based on these findings is that boundary-crossing strategies should better focus on motivation rather than on conditions to collaborate such as contracts, methods and instruments. Also, they should not prevent the emergence of boundary-crossing tactics, even if they appear to challenge these same strategies. Leaving room for improvisation seems to be essential in managing the boundaries between project-based organizations - like construction enterprises - and continuous-process organizations - like hospitals, boundaries that typically emerge while playing The Expansive Hospital game and also in the industry (Chinowsky, 2011, p. 4).

With respect to learning, sticking to boundary-crossing strategies without enabling boundary-crossing tactics may be expensive learning rather than expansive learning. The case of group B is emblematic to this point: boundary crossing was expensive to this group due to the negotiations based on exchange value; however, they still expanded learning beyond text reading. In an industry project, practitioners may not have the same opportunity for reflection after the failure. In that case, boundary crossing might be expensive only. The game analysis suggests that prioritizing exchange value in design negotiations leads to expensive learning, whereas prioritizing use value leads to expansive learning, yet this claim needs further confirmation from future studies.

Considering the attention given to integrative strategies in both design projects and literature studied, The Expansive Hospital game can be considered a critical statement on the way boundaries are currently dealt by design practice and theory. Instead of reporting these studies as a traditional case study - what may be done in the future, we have chosen to first design a game that recreates and expand the conflicts and see what students think about them. The goal was not to make the criticism directly, but to let players develop their own criticism about the situation, what Mary Flanagan calls 'critical play' (Flanagan, 2009). The usefulness - or playfulness - of critical play in communicating research findings to a broader audience remains to be seen.

Complex, contradictory and open-ended board games arise as a resource for collective reflection in design education and possibly in other fields, in particular, when dealing with emergent phenomena such as boundary crossing. These games seem to be particularly useful in expanding the object of learning beyond the text, getting closer to the related societal practices. Granted, playing games is safer and quicker than going through conflicts in practice, what could be useful for experienced practitioners too. In a rough comparison, it is possible to say that the contradiction between exchange value and use value was much tenser in the design projects studied than in the play activity, causing and being caused by uneasy business relationships among the firms involved. Future studies may explore the application of games to enable boundary-crossing strategies and tactics in design projects with multiple firms and stakeholders.

\section{Acknowledgements}

The authors would like to thank the design students for agreeing to join this study and the following persons for their comments on early drafts of this paper: Chris Seijger, Alexandr Vasenev, Hendrik Cramer, Wilma Bobbink and Rodrigo Gonzatto. The game described in this paper was commissioned by the BIM Workplace from Pioneering.

\section{Disclosure statement}

No potential conflict of interest was reported by the authors.

\section{Note}

1. Before this course, a couple of pilot experiments were organized with the authors performing as facilitators, explaining the rules and observing the game, which resulted in a much more strict playing by the rules. It was also experimented with individual learning reports, but the reflections were considered too shallow.

\section{References}

1830: Railways \& Robber Barons. 1986. Avalon Hill.

Akkerman, S.F. and Bakker, A. (2011) Boundary crossing and boundary objects. Review of Educational Research, 81(2), 132-69.

Aldrich, H. and Herker, D. (1977) Boundary spanning roles and organization structure. Academy of Management Review, 2(2), 217-30.

Askland, H.H., Gajendran, T. and Brewer, G. (2013) Project organizations as organizational fields: expanding the level of analysis through Pierre Bourdieu's Theory of Practice. Engineering Project Organization Journal, 3(2), 116-26.

Baiden, B.K., Price, A.D.F. and Dainty, A.R.J. (2006) The extent of team integration within construction projects. International Journal of Project Management, 24(1), 13-23.

Blau, J. (1984) Architects and Firms: A Sociological Perspective on Architectural Practices, MIT Press, Cambridge.

Bogers, M. and Sproedt, H. (2012) Playful collaboration (or not): using a game to grasp the social dynamics of open innovation in innovation and business education. Journal of Teaching in International Business, 23(2), 75-97.

Brown, T. (2008) Design thinking. Harvard Business Review, 86(6), 84-92, 141.

Bruggeman, E.M., Chao-Duivis, M.A.B. and Koning, A.Z.R., eds. (2010) A Practical Guide to Dutch Building Contracts, IBR Instituut voor Bouwrecht, The Hague.

Carlile, P.R. (2002) A pragmatic view of knowledge and boundaries: boundary objects in new product development. Organization Science, 13(4), 442-55.

Carlile, P.R. (2004) An integrative transferring, translating, and transforming: framework for managing knowledge across boundaries. Organization Science, 15(5), 555-68. 
Chanin, M.N. and Shapiro, H.J. (1985) Inquiry dialectical extending in the planning: strategic boundaries. The Academy of Management Review, 10(4), 663-75.

Cheng, M.-Y. and Tsai, M.-H. (2008) Cross-organization process integration in design-build team. Automation in Construction, 17(2), 151-62.

Chinowsky, P. (2011) Engineering project organization: defining a line of inquiry and a path forward. Engineering Project Organization Journal, 1(1), 3-10.

Cicmil, S. and Marshall, D. (2005) Insights into collaboration at the project level: complexity, social interaction and procurement mechanisms. Building Research \& Information, 33(6), 523-35.

Cleopatra and the Society of Architects (2006) Days of Wonder.

Denton, H.G. (1997) Multidisciplinary team-based project work: planning factors. Design Studies, 18(1997), 155-70.

Dossick, C.S. and Neff, G. (2010) Organizational divisions in BIM-enabled commercial construction. Journal of Construction Engineering and Management, 136(4), 459-67.

Eastman, C., Teicholz, P., Sacks, R. and Liston, K. (2009) BIM Handbook: A Guide to Building Information Modeling for Owners, Managers, Designers, Engineers and Contractors, John Wiley \& Sons, Hoboken, NJ.

Engeström, Y. (2000) Activity theory and the social construction of knowledge: a story of four umpires. Organization, 7 (2), 301-10.

Engeström, Y. (2001) Expansive learning at work: toward an activity theoretical reconceptualization. Journal of Education and Work, 14(1), 133-56.

Engeström, Y. (2006) Activity theory and expansive design, in Smith, G.C. and Bagnara, S. (eds.) Theories and Practice in Interaction Design, Lawrence Earlbaum Associates, Hillsdale, NJ, pp. 3-24.

Engeström, Y. (2008) From Teams to Knots, Cambridge University Press, Cambridge.

Engeström, Y. (2011) From design experiments to formative interventions. Theory \& Psychology, 21(5), 598-628.

Engeström, Y. (2015) Learning by Expanding. An ActivityTheoretical Approach to Developmental Research, 2nd edn, Cambridge University Press, New York.

Engeström, Y. and Sannino, A. (2010) Studies of expansive learning: foundations, findings and future challenges. Educational Research Review, 5(1), 1-24.

Engeström, Y., Engeström, R. and Kärkkäinen, M. (1995) Polycontextuality and boundary crossing in expert cognition: learning and problem solving in complex work activities. Learning and Instruction, 5(4), 319-36.

Flanagan, M. (2009) Critical Play: Radical Game Design, MIT Press, Cambridge.

Forgues, D., Koskela, L. and Lejeune, A. (2009) Information technology as boundary object for transformational learning. Journal of Information Technology in Construction, 14 (2009), 48-58.

Gonzatto, R.F., Amstel, F.M.C. Van and Costa, R.C.T. (2010) Jogos e Humor nas Metodologias de Design, in Proceedings do IX SBGames, Florianópolis, Brasil, pp. 138-44.

Gottlieb, S. and Haugbølle, K. (2013) Contradictions and collaboration: partnering in-between systems of production, values and interests. Construction Management and Economics, 31(2), 119-34.

Habraken, N. and Gross, M. (1988) Concept design games. Design Studies, 9(3), 150-58.
Hannele, K., Reijo, M., Tarja, M., Sami, P., Jenni, K. and Teija, R. (2012) Expanding uses of building information modeling in life-cycle construction projects. Work: A Journal of Prevention, Assessment and Rehabilitation, 41(2012), 114-19.

Hartmann, A. and Bresnen, M. (2011) The emergence of partnering in construction practice: an activity theory perspective. Engineering Project Organization Journal, 1(1), 41-52.

Hasu, M. and Engeström, Y. (2000) Measurement in action: an activity-theoretical perspective on producer-user interaction. International Journal of Human-Computer Studies, 53(1), 61-89.

Hatchuel, A. (2001) Towards design theory and expandable rationality: the unfinished program of Herbert Simon. Journal of Management and Governance, 5(3), 260-73.

Holzer, D. (2007) Are you talking to me? BIM alone is not the answer, in Kirsten Orr, S.K.-O. (ed.) Proceedings of the Fourth International Conference of the Association of Architecture Schools of Australasia, Sydney, Australia.

Kaptelinin, V. and Uden, L. (2012) Understanding delegated actions: toward an activity-theoretical perspective on customer-centred service design, in Tossavainen, P.J., Harjula, M. and Holmlid, S. (eds.) Proceedings of ServDes.2012: Nordic Conference on Service Design and Service Innovation, Espoo, Finland, pp. 101-9.

Kelley, D. and Van Patter, G.K. (2005) Design as glue. Understanding the Stanford D. School. NextD Journal Conversation, (21), 1-9.

Kerosuo, H. (2004) Examining boundaries in health care outline of a method for studying organizational boundaries in interaction. Outlines. Critical Practice Studies, 6(1), $35-60$.

Kuhn, S. (2001) Learning from the architecture studio: implications for project-based pedagogy. International Journal of Engineering Education, 17(4-5), 349-52.

Kunz, W. and Rittel, H.W.J. (1970) Issues as Elements of Information Systems, Berkeley, CA, No. 131.

Lahdenperä, P. (2012) Making sense of the multi-party contractual arrangements of project partnering, project alliancing and integrated project delivery. Construction Management and Economics, 30(1), 57-79.

Lefebvre, H. (1972) El manifiesto diferencialista, Siglo XXI, Ciudad del Mexico.

Lefebvre, H. (1991) The Production of Space, Wiley-Blackwell, Oxford.

Lefebvre, H. (2014a) Toward an Architecture of Enjoyment, University of Minnesota Press, Minneapolis.

Lefebvre, H. (2014b) Critique of Everyday Life, Verso, London. Master Builder (2008) Valley Games, Inc.

Miettinen, R. and Paavola, S. (2014) Beyond the BIM utopia: approaches to the development and implementation of building information modeling. Automation in Construction, 43(2014), 84-91.

Neff, G., Fiore-Silfvast, B. and Dossick, C.S. (2010) A case study of the failure of digital communication to cross knowledge boundaries in virtual construction. Information, Communication \& Society, 13(4), 556-73.

Pahl, G., Beitz, W., Wallace, K. and Council, D. (1984) Engineering Design: A Systematic Approach, Springer, London.

Pemsel, S. and Widén, K. (2011) Bridging boundaries between organizations in construction. Construction Management and Economics, 29(5), 495-506. 
Räisänen, C. and Löwstedt, M. (2014) Stakes and struggles in liminal spaces: construction practitioners interacting with management-consultants. Engineering Project Organization Journal, 4(2-3), 1-11.

Ramirez, R. (1999) Value co-production: intellectual origins and implications for practice and research. Strategic Management Journal, 20(1), 49-65.

Rau, C., Neyer, A.-K. and Möslein, K.M. (2012) Innovation practices and their boundary-crossing mechanisms: a review and proposals for the future. Technology Analysis \& Strategic Management, 24(2), 181-217.

Sacks, R., Esquenazi, A. and Goldin, M. (2007) LEAPCON: simulation of lean construction of high-rise apartment buildings. Journal of Construction Engineering and Management, 133(7), 529-39.

Salen, K. and Zimmerman, E. (2004) Rules of Play: Game Design Fundamentals, MIT Press, Cambridge.

Schön, D.A. (1983) The Reflective Practitioner: How Professionals Think in Action, Basic Books, New York.

Selvin, A., Buckingham Shum, S., Seirhuis, M., Conklin, J., Zimmerman, B., Charles, P., Drath, W., Horth, D., Domingue, J., Motta, E. and Li, G. (2001) Compendium: making meetings into knowledge events, in Knowledge Technologies 2001, Austin, TX, USA, pp. 4-7.

Singh, V., Gu, N. and Wang, X. (2011) A theoretical framework of a BIM-based multi-disciplinary collaboration platform. Automation in Construction, 20(2), 134-44.
Star, S.L. (2010) This is not a boundary object: reflections on the origin of a concept. Science, Technology \& Human Values, 35(5), 601-17.

Suchman, L. (1994) Working relations of technology production and use. Computer Supported Cooperative Work 2(1-2), 21-39.

The Pillars of the Earth (2006) 999 Games.

Tsuru (2004) Abysse Corp.

Ugg-Tect (2009) Edge Entertainment.

Vargo, S.L., Maglio, P.P. and Akaka, M.A. (2008) On value and value co-creation: a service systems and service logic perspective. European Management Journal, 26(3), 145-52.

Vygotsky, L. (1978) Mind in Society, Harvard University Press, Cambridge, MA.

Vygotsky, L.S. (1967) Play and its role in the mental development of the child. Journal of Russian and East European Psychology, 5(6), 6-18.

Ward, A. (1990) Ideology, culture and the design studio. Design Studies, 11(1), 10-16.

\section{Appendix}

The following tables are appended together to enable understanding the inversion from induced to produced differences in the experiment with the Expansive Hospital game.

Table A1 Differences induced to players of the Expansive Hospital game as if each role an activity system was

\begin{tabular}{|c|c|c|c|c|c|c|}
\hline Subject & Object & Outcome & Instruments & Rules & Community & Division of labour \\
\hline Nurse & $\begin{array}{l}\text { Patients in the } \\
\text { queue }\end{array}$ & $\begin{array}{l}\text { Treated } \\
\text { patients }\end{array}$ & $\begin{array}{l}\text { Satisfaction } \\
\text { points }\end{array}$ & $\begin{array}{l}\text { Patients may leave } \\
\text { treatment }\end{array}$ & Healthcare team & Managing the patient queue \\
\hline $\begin{array}{l}\text { Facility } \\
\text { manager }\end{array}$ & Treated patients & Programme & Building blocks & $\begin{array}{l}\text { Must keep track of assets to } \\
\text { earn }\end{array}$ & & $\begin{array}{l}\text { Suggesting the blocks to be } \\
\text { built }\end{array}$ \\
\hline Director & Programme & Budget & Contracts & $\begin{array}{l}\text { Income depends on } \\
\text { investments }\end{array}$ & & Choosing a contract \\
\hline Architect & Budget & Building layout & Budget & Design should be holistic & \multirow{3}{*}{$\begin{array}{l}\text { Construction } \\
\text { team }\end{array}$} & Defining the blocks' position \\
\hline Engineer & Building layout & Pipework & Pipe tiles & Profit from service synergy & & Designing the pipework \\
\hline Contractor & Pipework & Building blocks & Building blocks & May charge inspections & & Gatekeeping the blocks \\
\hline
\end{tabular}

Table A2 Differences produced by design students from group A and B, in italic

\begin{tabular}{|c|c|c|c|c|c|c|c|}
\hline Gr. & Subject & Object & Outcome & Instruments & Rules & Community & Division of labour \\
\hline \multirow[t]{3}{*}{$\bar{A}$} & $\begin{array}{l}\text { Nurse } \\
\text { Facility manager } \\
\text { Director }\end{array}$ & Patients & Profitable hospital & $\begin{array}{l}\text { Care plan } \\
\text { Building inventory } \\
\text { Contracts, personal } \\
\text { income statement }\end{array}$ & Operational efficiency & $\begin{array}{l}\text { Healthcare } \\
\text { team }\end{array}$ & $\begin{array}{l}\text { Collaborate among each other } \\
\text { and try to interfere with the } \\
\text { other team's decisions }\end{array}$ \\
\hline & $\begin{array}{l}\text { Architect } \\
\text { Engineer }\end{array}$ & Design & Integrated facilities & $\begin{array}{l}\text { Budget } \\
\text { Pipe tiles, Pipework } \\
\text { sketch }\end{array}$ & Design efficiency & $\begin{array}{l}\text { Construction } \\
\text { team }\end{array}$ & $\begin{array}{l}\text { Collaborate among each other } \\
\text { and try to interfere with the } \\
\text { other team's decisions }\end{array}$ \\
\hline & Contractor & & & Building blocks & & & \\
\hline \multirow[t]{6}{*}{ B } & Nurse & $\begin{array}{l}\text { Patients in } \\
\text { the queue }\end{array}$ & $\begin{array}{l}\text { Logical path for } \\
\text { patients }\end{array}$ & Building blocks & $\begin{array}{l}\text { Strategically positioning } \\
\text { the blocks }\end{array}$ & Whole group & Try to influence other actors \\
\hline & Facility manager & $\begin{array}{l}\text { Available } \\
\text { blocks }\end{array}$ & Unneeded blocks & Building blocks & $\begin{array}{l}\text { Building the most } \\
\text { expensive }\end{array}$ & & $\begin{array}{l}\text { Push orders to the construction } \\
\text { team }\end{array}$ \\
\hline & Director & $\begin{array}{l}\text { Credibility } \\
\text { rating }\end{array}$ & Team orientation & $\begin{array}{l}\text { Contracts, } \\
\text { expenditures } \\
\text { statement }\end{array}$ & $\begin{array}{l}\text { Income depends on } \\
\text { investments }\end{array}$ & & Choosing a contract \\
\hline & Architect & Income & $\begin{array}{l}\text { Useless building that } \\
\text { cannot treat the }\end{array}$ & Building blocks & $\begin{array}{l}\text { Design for service } \\
\text { synergy }\end{array}$ & & Defining the blocks' position \\
\hline & Engineer & & patients in the queue & Pipe tiles & $\begin{array}{l}\text { Build superfluous } \\
\text { pipework }\end{array}$ & & Designing the pipework \\
\hline & Contractor & & & Building blocks & $\begin{array}{l}\text { Charge as much as } \\
\text { possible }\end{array}$ & & Gatekeeping the blocks \\
\hline
\end{tabular}

